\title{
Risk Identification Model for Enterprise Sustainable Crowdsourcing Innovation Based on BSC
}

\author{
Qingliang Meng*, Huiyun Shan \\ School of Economics and Management, Jiangsu University of Science and Technology, Jiangsu, China \\ *Corresponding author. Email: mengzhi007@163.com
}

\begin{abstract}
The provision of creative intelligence to enterprise is a global endeavor and a great challenge to managers. As a new business model, crowdsourcing innovation act as an effective way to exploit and utilize internal and external wisdom in boosting enterprise innovation quality and quantity. However, with the features of loose boundaries, free voluntary participants, complex and diverse tasks, risks are directly related to the sustainable crowdsourcing innovation performance. Considering the structural management system for enterprise development, this paper introduces the novel theory of Balanced Score Card, which can balance internal and external factors, financial and non-financial goals. And a BSC-based crowdsourcing innovation strategy map and risk identification model was established from a strategic perspective. This paper provides a framework to managers for effective identification of crowdsourcing innovation risks.
\end{abstract}

Keywords: Crowdsourcing innovation, Risk identification, BSC.

\section{INTRODUCTION}

As a new business model, crowdsourcing innovation transfers tasks executed by internal employees to external non-specific network users in a free and voluntary form ${ }^{[1]}$. The enterprise can gather resources at most and drive the organization to innovate sustainably.

It is highly regarded because it can integrate external innovation resources effectively and achieve innovation goals quickly. Depend on the InnoCentive innovation community, $R \& D$ expenditure in $P \& G$ is reduced by $50 \%$ and innovation output is increased by $60 \%$. To predict customer preferences, a $\$ 1$ million reward is offered by Netflix for recruiting crowdsourcing innovation teams. And the algorithm precision is increased by $10 \%$. It has received widespread attention for its advantage in reducing innovation risks and improving innovation efficiency. However, the enterprises pay too much attention to performance in solving innovation problems, ignoring the organization compatibility. Many problems do exist, such as immature business models, chaotic innovation processes, low stickiness of contractors and severe homogeneity of innovation results, interrupting the sustainable yield of crowdsourcing innovation. Although crowdsourcing innovation virtual communities have been established by domestic enterprises like Zhubajie and Haier, tasks are too single and simple. Also, the lack of mainstream enterprises' participation is in striking contrast to foreign enterprises' attention on crowdsourcing innovation ${ }^{[2]}$. To manage risks that affect the innovation performance, this paper is set out to answer the question: How can the enterprises identify crowdsourcing innovation risks exhaustively to keep sustainable crowdsourcing process going?

The main purpose of crowdsourcing innovation is to acquire external and internal knowledge for continuous creativity intelligence, so that it can achieve mutual knowledge penetration, communication and cooperation, interactive innovation between the initiator and solvers on crowdsourcing platforms. So, whether participants can share knowledge continuously, whether the process is appropriate, have become the key uncertainties that affect sustainable crowdsourcing performance. BSC, as a systematic strategic management tool that describes the specific implementation process of enterprises operation, has the advantages of balancing internal and external elements of the organization, taking into account the causality, and integrating financial and non-financial goals $^{[3]}$. Consequently, this paper, conducts a systematic study on crowdsourcing innovation risks based on BSC.

\section{LITERATURE REVIEW}

\subsection{Crowdsourcing Innovation Business Model}

Crowdsourcing innovation plays a vital role in 
accelerating knowledge absorption.

Many scholars carried out research on crowdsourcing innovation. Zhao etal.(2014) constructed a framework involving components, processes, and actions, including the crowdsourcing initiator, crowdsourcing platform and the solver ${ }^{[4]}$. Feng(2015) explained process from three dimensions. Crowdsourcing innovation activities are faced with uncertainties, such as internal and external turbulence and uncertainty of value ${ }^{[5]}$. Simultaneously, the crowdsourcing gets out of control for the solver's withdrawal randomly. So, as initiator, the enterprise's scientific understanding and governance of the risks is crucial. Ultimately, it enables sustainable crowdsourcing to promote the enterprise's continuous innovation.

\subsection{Crowdsourcing Innovation Risks}

Risks are related to the sustainable crowdsourcing innovation performance, with the following features: the virtuality of organizational environment and looseness of the corporate form, the voluntary and dynamic nature of the participants, asymmetry and difficulty of information exchange. Namely, this paper defines crowdsourcing innovation risks as uncertainties that affect innovation tasks and disrupt the crowdsourcing innovation process. Meanwhile, risk management is regarded as an effective means to improve innovation performance. To this end, relevant scholars have carried out useful explorations on the risk management issues on crowdsourcing innovation:

(1) Composition of crowdsourcing innovation risks. Liu (2016) proposed five risks in crowdsourcing, which have various impacts on innovation performance. They are crowd-sourced risk, relationship risk, complexity risk, demand risk, and task risk ${ }^{[6]}$. Gao (2016) believed in four types of capability risk: organizational management risk, intellectual property risk, and information risk ${ }^{[7]}$. Lu (2018) summarized four types of trouble from the solver's perspective: resource waste, risk of outcome quality and mortality, and intellectual property risk ${ }^{[8]}$.

(2) Risk control of crowdsourcing innovation. Ding etal.(2019) explored risk control problems with the differential game model from a multi-perspective of the crowdsourcing platform and participants ${ }^{[9]}$. According to the behavioural theory, Zhang Hua etal.(2019) explained the opportunistic risk caused by unclear ownership and put forward corresponding countermeasures ${ }^{[10]}$.

Existing scholars have analyzed the risk sources and countermeasures from multiple perspectives. However, research results are very scattered, and structural methods are scarcely needed to identify risk source systematically. Relevant research on crowdsourcing innovation from a strategic perspective is still scarce.

\subsection{Risk Management Based on BSC}

Designed from the enterprise vision, BSC's core idea is to show the organization's strategic trajectory through mutually-driven causal relationship. Thereby, unification of short-term performance and sustainable development is realized. With the changes of environment, enterprises must take comprehensive view of enterprise risks and establish a risk management framework. Elevating risk management to a strategic level is strongly supported.

In terms of innovation management, Blohm I (2011) developed an open-innovation community scorecard that consists of an innovation process, a community member, an organizational learning and a financial perspective ${ }^{[11]}$. Meanwhile, Manville (2019) developed the theory of knowledge management and organizational performance within a small enterprise context using action research ${ }^{[12]}$.

In terms of risk management, $\mathrm{Hu}(2016)$ improved the indicator system and operation mechanism of the riskoriented balanced scorecard ${ }^{[13]}$. Mandy M.(2018) pointed out that BSC provides a useful framework for integrating strategic risk and performance information. Managers must make strategic judgments on how to combine strategic risk and performance information ${ }^{[14]}$. The forensic accounting strategy map can effectively realize the quality assurance of corporate governance and antifraud, which has implications for decision-makers.

It has been appreciated that the locus of innovation span organizational boundaries. And, it is undoubtedly a specific perspective and innovative study by exploring the uncertainties from particular implementation path. Thus, a risk management framework is formed.

\section{RISK IDENTIFICATION MODEL FOR CROWDSOURCING INNOVATION BASED ON BSC}

\subsection{BSC's Advantages in Risk Identification of Crowdsourcing Innovation}

The BSC aims to decompose the strategic objectives into operable measurement indicators under the four dimensions of finance, customers, internal processes, and learning and growth. It demonstrates strategic trajectory from bottom to top. With the inherent features, there are many uncertainties in specific implementation process. Source of crowdsourcing innovation risks are identified comprehensively and multi-dimensionally by integrating the ideas of BSC and process of crowdsourcing innovation strategies. So, uncertainties are discovered from specific implementation path of the strategy map ${ }^{[17]}$.

(1) Based on the BSC, the implementation path of the crowdsourcing innovation strategy can be depicted, and source of uncertainty can be identified. The construction of crowdsourcing innovation strategy map based on BSC can clarify specific uncertainties that come from multiple dimensions and affect overall innovation performance.

(2) A set of structural methods is provided by BSC. It 
identifies risks from the four dimensions of finance, customers, internal processes, and learning and growth. Unlike multi-criteria evaluation ideas, risk identification of crowdsourcing innovation based on BSC is systematic and structurally, contributing to the construction of the risk identification model's reliability and stability.

(3) Multiple factors are taken into account by BSC, such as technology and business, results and causes, past and future, which provides objective measurement idea. It is consistent with novel crowdsourcing innovation theory, which focus on sustainable performance.

\subsection{Crowdsourcing Innovation Strategy Map Based on BSC}

Combining the principles of BSC and the advanced theory of crowdsourcing innovation, the paper constructs a crowdsourcing innovation strategy map. It indicates the implementation path of crowdsourcing innovation, which is ensured by the technical and cultural from the learning and growth dimension. Smooth operation is supported from the internal processes dimension. The importance of maintaining solver's source that promotes continuous innovation is emphasized from the customer dimension. The overall requirement for crowdsourcing innovation performance is judged from a financial perspective.

(1) Financial dimension: Innovation performance includes ultimate efficiency and effect of creation, which is shown in many aspects, like product innovation, innovation speed and quantity, and increased revenue. Crowdsourcing is process of collaborative creation among enterprises, users, and crowdsourcing platforms.

(2) Customer dimension answered how to increase the solver's participation willingness and exert their creativity for crowdsourcing innovation performance. It pays attention to the solver's satisfaction with the process and communication. Reward, communication and distribution mechanism of crowdsourcing innovation will affect initiator's loyalty. To improve the relational values, it creates a high-level platform interaction for a mutually beneficial crowdsourcing environment. In this way, trust and relationship commitment level is improved.

(3) The internal process dimension mainly supports the realization of loyalty and crowdsourcing initiator's relational enhancement. For this reason, it is necessary to optimize process of crowdsourcing innovation. The whole process starts from the task decomposition, the requirements release, matching of contractors, evaluation of solutions, and distribution of rewards. These factors affect the relationship and satisfaction between multiple participants are found. Also, the most efficient and effective internal process management plan is established.

(4) To support the efficient operation of internal processes, the learning and growth dimension describes how to effectively integrate technology, organizational culture, and human resources. It requires a high level of information technology, a reliable and stable information systems to prevent intellectual property leakage and evade participants' opportunistic behaviours. It's essential to realize the crowdsourcing innovation strategy by creating a cultural atmosphere of openness and sharing. Employee quality and technique are also crucial factors that determine the innovation process. It's necessary to strengthen employees' ability in absorbing external knowledge and enterprise's original "knowledge base".

\subsection{Risk Identification of Crowdsourcing Innovation}

Crowdsourcing innovation has many significant uncertainties, which triggers various risks. Therefore, this paper discovered these factors by the crowdsourcing innovation strategy map, as shown in Figure 1.

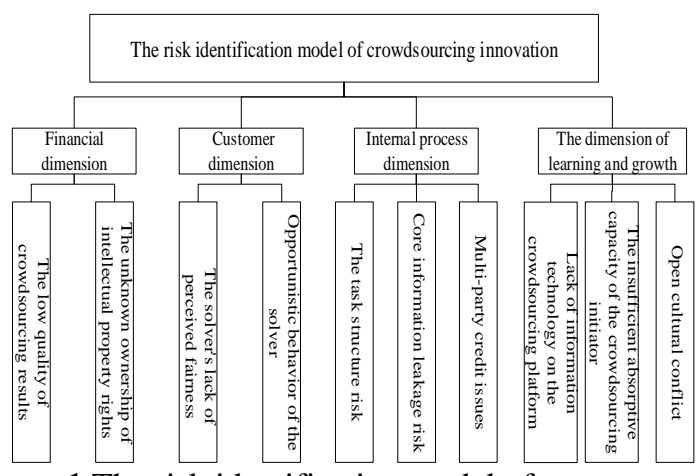

Figure 1 The risk identification model of crowdsourcing innovation

(1) Financial dimension: It is investigated from the uncertainty that affects the performance. The obtained solutions deviate from the initiator's requirements, which results in a waste of resources of the initiator. Innovation results have the problem of unclear ownership in the received products, such as the revelation of innovative solutions by participants, which causes the intellectual property to drain and damages the performance.

(2) Customer dimension: It is analyzed from the uncertainty of the solver's satisfaction. Crowdsourcing management process is cumbersome. Task authorization and supervision are not synchronized, which leads to confusion and low interaction. It will harm the interests and enthusiasm of the initiator, resulting in an intense participation experience. To maximize its interests, the solver takes opportunistic behaviours, like plagiarizing others plans or multiplying contributions with one manuscript, resulting in intellectual property disputes.

(3) Internal process dimension: It is analyzed from the uncertainty in crowdsourcing innovation process. Tasks of the crowdsourcing initiator are complicated. The subtasks are not scientifically decomposed or exceed the scope of the solver's capabilities, which causes the task's ineffective progress. The degree of cooperation and sharing is too high, which leads to the leakage of internal 
information and jeopardizes the interests of the initiator. Lack of trust among participants leads to loose process in crowdsourcing innovation, like the passive participation, deferred bonuses, and loopholes in platform management.

(4) The dimension of learning and growth: It's studied from uncertainty of the initiator's capabilities. Functions on crowdsourcing platform systems are lack, such as the lack of interaction between members and the lack of visualization tools, which will result in communication delay. The solver lacks crowdsourcing experience. Task's difficulty exceeds the solver's integration ability. Also, restructure takes place too frequently, leading to chaotic management in internal human resource.

\section{CONCLUSION}

This paper combines the significant advantages of BSC to discuss the construction of risk identification models for crowdsourcing innovation.

\section{AUTHORS’ CONTRIBUTIONS}

The main contributions are as follows: it constructed a BSC-based crowdsourcing innovation strategy map and identified uncertainties from the four perspectives of finance, customers, internal processes, learning and growth, which affect crowdsourcing innovation goals. This paper provides a framework to managers for effective identification of crowdsourcing innovation risks. Manager's decisiveness and operational flexibility can be gained through analytical capabilities.

\section{ACKNOWLEDGMENTS}

The authors thank the editors and the referees for carefully reading the paper.

This paper is funded by The Ministry of education of Humanities and Social Science project of China (No: 19YJA630055); Jiangsu Social Science Fund project (No:20GLB016).

\section{REFERENCES}

[1] Howe, J, The rise of crowdsourcing. Wired Mag. vol. 14, 2006, pp. 1-4. DOI:10.1086/599595

[2] Mack, T., \& Landau, C, Submission quality in open innovation contests-an analysis of individual-level determinants of idea innovativeness. R\&D Management, vol: 50, WILEY, NJ USA, 2020, pp. 47-62. DOI: https://doi.org/10.1111/radm.12345

[3] Kaplan, R., The balanced scorecard-measures that drive performance. Harvard Business Review, vol: 70, HARVARD BUSINESS REVIEW, BOULDER, CO, 1992, pp. 71-79.

[4] Zhao Y, Zhu Q., Evaluation on crowdsourcing research: Current status and future direction.
Information Systems Frontiers, vol:16, SPRINGER, NETHERLANDS, 2014, pp. 417-434. DOI: https://doi.org/10.1007/s10796-012-9350-4

[5] Feng J.H., Li G.L., Overview of crowdsourcing technology research. Chinese Journal of Computers, vol: 9, 2015, pp. 1713-1726. DOI: 10.11897/SP.J.1016.2015.01713

[6] Liu, S., etal, Exploring the trends, characteristic antecedents, and performance consequences of crowdsourcing project risks. International Journal of Project Management, vol: 34, ELSEVIER, ENGLAND, 2016, pp. 1625-1637. DOI: https://doi.org/10.1016/j.ijproman.2016.09.002

[7] Gao M. \& Wang Y., Research on the Risk Assessment Model of Crowdsourcing Projects. Management Modernization, vol: 36, 2016, pp. 105107. DOI: 10.3969/j.issn.1003-1154.2016.03.032

[8] Lu X.Y., Huang H., etal, Research on Influencing Factors of Innovative Performance of Contractors in Crowdsourcing Competitions. Chinese Journal of Management, vol: 15, 2018, pp. 750-758. DOI: 10.3969/j.issn.1672-884x.2018.05.015

[9] Liu W., etal, Research on the Risk Control Mechanism of Network Crowdsourcing Default Based on Differential Game. System Engineering Theory and Practice, vol:39, 2019, pp. 2559-2568. DOI: CNKI: SUN: XTLL.0.2019-10-010.

[10] Zhang H., Gu X., etal, The Opportunistic Risk of Open Innovation and Its Governance Mechanism. Scientific Management Research, vol: 37, 2019, DOI: 10.19445/j.cnki.15-1103/g3.2019.05.003.

[12] Manville Graham, Karakas Fahri, etal. Supporting open innovation with the use of a balanced scorecard approach: a study on deep smarts and effective knowledge transfer to SMEs. Production Planning \& Control, vol: 30, TAYLOR \& FRANCIS LTD, OXON, ENGLAND, 2019, pp. 1012. DOI: $10.1080 / 09537287.2019 .1582093$

[13] Hu Y.M., Chi G.H., Research on the Risk-Oriented Balanced Scorecard in Performance EvaluationBased on the Case Study of YC Company. Finance and Accounting, vol: 17, 2016, pp.72-75. DOI: CNKI:SUN:CWKJ.0.2016-17-037

[14] Mandy M. Cheng, Kerry A, etal, The interplay between strategic risk profiles and presentation format on managers' strategic judgments using the balanced scorecard. Accounting, Organizations and Society, vol: 70, ELSEVIER, ENGLAND,2018, DOI: 10.1016/j.aos.2018.05.009 